\title{
Pengaruh Pemanfaatan Media Sosial Instagram Terhadap Minat Berwirausaha Mahasiswa Fakultas Ekonomi dan Bisnis Universitas Mataram
}

\author{
Emi Salmah $^{* 1}$, Luluk Fadliyanti ${ }^{2}$, Siti Sriningsih ${ }^{3}$ \\ ${ }^{123}$ Fakultas Ekonomi Dan Bisnis Universitas Mataram
}

*Coresponding Email: emisalmah0101@gmail.com

\begin{tabular}{ll}
\hline \multicolumn{1}{c}{ Info Artikel } & \multicolumn{1}{c}{ ABSTRAK } \\
\hline Kata Kunci: & Berwirausaha dapat dilakukan dengan memanfaatkan teknologi dan \\
Media Sosial, Interaksi, & media sosial yang ada, seperti saat ini semua orang dapat dengan \\
Aksesabilitas, Minat & mudah mengakses bahkan memiliki akun media sosial yang dapat \\
Berwirausaha & digunakan untuk berbagi informasi baik berupa foto ataupun vidio. \\
& Instagram merupakan salah satu media sosial yang paling diminati \\
& para generasi milenial dan banyak menggunakan 4 platform media \\
& sosial, yakni Instagram, Snapchat, Youtube dan Fecebook. Tujuan \\
& dari penelitian ini adalah untuk mengetahui seberapa besar \\
& pengaruh pemanfaatan media sosial instagram terhadap minat \\
& berwirausaha mahasiswa Fakultas Ekonomi Dan Bisnis Universitas \\
& Mataram. Pengumpulan data melalui penyebaran kuesioner. Teknik \\
& analisis yang digunakan regresi linier berganda. Hasil penelitian \\
& menunjukkan variabel dependen komunitas online (X1), secara \\
& parsial tidak berpengaruh signifikan terhadap variabel independen \\
& minat berwirausaha (Y), sedangkan variabel interaksi (X2), dan \\
& variabel aksesabilitas (X3) secara parsial masing - masing \\
& berpengaruh signifikan terhadap minat berwirausaha (Y). Dan \\
& secara simultan semua variabel dependen komunitas online (X1), \\
& interaksi (X2), dan aksesabilitas (X3) secara bersamaan berpengaruh \\
& signifikan terhadap minat berwirausaha (Y). Sedangkan berdasarkan \\
& hasil deteksi asumsi klasik menunjukkan kondisi model tidak dalam \\
& masalah multikoloniaritas, tidak mengandung heteroskedastisitas \\
dan menunjukkan kondisi normal.
\end{tabular}

\section{PENDAhULUAN}

Perkembangan zaman dan penggunaan teknologi sudah semakin maju, Indonesia merupakan salah satu negara berkembang yang tidak bisa menolak jika sudah memasuki era revolusi industri 4.0, pada fase ini ditandai dengan kemajuan teknologi yang semakin canggih yang digunakan diberbagai sektor. Hal ini digunakan untuk mengefisienkan waktu produksi, kurangnya tenaga kerja yang dibutuhkan dan meminimumkan biaya produksi yang dikeluarkan, sehingga akan diperoleh keuntungan yang 


\section{Elastisitas - Jurnal Ekonomi Pembangunan \\ Vol. 3 No. 2, September 2021}

maksimal. Selain itu juga, seiring dengan perkembangan teknologi yang dibarengi dengan perkembangan jejaring sosial seperti Youtube, Facebook, Instagram Twitter, Line, Pinterest, Whatsapp, Fb Messenger, Snapchat, dan Viber dan lain lain merupakan media sosial yang sering diakes oleh semua orang. Berdasarkan laporan terbaru we are social, pada tahun 2020 disebutkan bahwa ada 175,4 juta pengguna internet di Indonesia. Di bandingkan tahun sebelumnya, ada kenaikan $17 \%$ atau 25 juta pengguna internet di negeri ini. Berdasarkan jumlah populasi Indonesia yang berjumlah 272,1 juta jiwa, maka itu artinya $64 \%$ penduduk RI telah merasakan akses ke dunia maya (Agus,2020). Untuk lebih jelasnya, dapat dilihat tabel 1 berikut:

Tabel 1.

Platform Media Sosial Yang Paling Banyak Diaksesdi Indonesia Persentase Pengguna Internet Berusia 16 Hingga 64 Tahun Yang Melaporkan Menggunakan Setiap Platform Januari 2020

\begin{tabular}{|l|l|r|r|}
\hline \multirow{2}{*}{ No } & \multicolumn{1}{|c|}{ Media Sosia } & Jumlah (Orang) & $\begin{array}{c}\text { Persentase } \\
\text { \% }\end{array}$ \\
\hline 1 & Youtube & 21.378 .393 & 12,2 \\
\hline 2 & Whatsapp & 20.406 .648 & 11,6 \\
\hline 3 & Facebook & 19.920 .776 & 11,4 \\
\hline 4 & Instagram & 19.191 .967 & 11 \\
\hline 5 & Twitter & 13.604 .432 & 7,8 \\
\hline 6 & Line & 12.146 .814 & 6,9 \\
\hline 7 & Facebook Masangger & 12.146 .814 & 6,9 \\
\hline 8 & Linkedin & 8.502 .770 & 4,8 \\
\hline 9 & Pinterest & 8.259 .834 & 4,7 \\
\hline 10 & Wechat & 7.045 .152 & 4 \\
\hline 11 & Snapchat & 6.802 .261 & 3,9 \\
\hline 12 & Skype & 6.073 .407 & 3,5 \\
\hline 13 & Tiktok & 6.073 .407 & 3,5 \\
\hline 14 & Tumblr & 5.344 .598 & 3 \\
\hline 15 & Reddit & 4.372 .853 & 2,4 \\
\hline 16 & Sina weibo & 4.129 .917 & 2,4 \\
\hline & & $\mathbf{1 7 5 . 4 0 0 . 0 0 0}$ & $\mathbf{1 0 0}$ \\
\hline
\end{tabular}

Sumber : hotsuijan 2020(data diolah)

Berdasarkan tabel di atas kita dapat mengambil 5 (lima) besar akun media sosial yang paling sering diakses atau banyak digunakan, media sosial yang menduduki peringkat pertama ialah youtube sebesar 12,2 persen, peringkat ke dua ada whatsap dengan jumlah sebesar 11,6 persen kemudian facebook dengan jumlah 11,4 persen, instagram dengan jumlah 11persen dan diurutan ke 5 ada twitter dengan jumlah pengguna sebanyak 7,8 persen, sisanya jenis sosial media lainnya. Dengan perkembangan teknologi yang pesat, dibutuhkan sumber daya manusia yang memiliki kualitas dan skil yang baik sehingga dapat memanfaatkan dan mengoprasikannya dengan baik pula. Untuk menghasilkan sumberdaya manusia yang baik dapat diperoleh melalui pendidikan baik pendidikan formal maupun nonformal. Melalui pendidikan formal dapat diawali dengan menempuh pendidikan mulai dari sekolah dasar sampai dengan perguruan tinggi, namun hal tersebut membutuhkan waktu yang cukup lama dan biaya yang 


\section{Elastisitas - Jurnal Ekonomi Pembangunan \\ Vol. 3 No. 2, September 2021}

tidak sedikit. Dan untuk pendidikan non formal dapat dilakukan dengan mengikuti program-program pelatihan salah satu lembaga pelatihan adalah BLK (Balai Latihan Kerja). Terdapat berbagai jenis pengangguran, salah satunya pengangguran terbuka . International Labor Organization (ILO) memberikan definisi Pengangguran terbuka adalah seseorang yang termasuk kelompok penduduk usia kerja yang selama periode tertentu tidak bekerja, dan bersedia menerima pekerjaan, serta sedang mencari pekerjaan. Pengangguran terbuka dilihat dari tingkat pendidikan yang ditamatkan atau disebut dengan pengangguran terdidik biasanya disebabkan oleh kurangnya lapangan pekerjaan sehingga tidak dapat menyerap semua tenaga kerja yang ada, tidak mau bekerja, atau adanya ketidakcocokan antara lowongan kerja yang ada dengan latar belakang pendidikan. Badan Pusat Statistik Propinsi NTB merilis kondisi ketenagakerjaan di Propinsi NTB pada Februari 2020, dalam setahun terakhir, pengangguran berkurang sekitar 3.07 ribu orang, sejalan dengan Tingkat Pengangguran Terbuka (TPT) yang turun menjadi 3,14 persen pada Februari 2020. Dilihat dari tingkat pendidikan, TPT untuk SMA Kejuruan tertinggi diantara pendidikan lain, yaitu sebesar 6,97 persen. Tingkat Pengangguran Terbuka (TPT) tertinggi berikutnya terdapat pada Perguruan Tinggi baik Diploma maupun S1 yaitu sebesar 6,27 persen masih terbilang cukup tinggi. (https://disnakertrans.ntbprov.go.id)

Dengan melihat fenomena yang terjadi, untuk menekan jumlah pengangguran terdidik di Provinsi Nusa Tenggara Barat, Fakultas Ekonomi dan Bisnis Universitas Mataram yang jumlah mahasiswa 4.893 mahasiswa pada Tahun Ajaran 2019/2020 (Akademik UNRAM,2020), mengharapkan mahasiswanya untuk dapat memulai berwirausaha sembari menyelesaikan pendidikan.

Menurut Bambang Sad Kurnianto dan Sulistya Ika Putra dalam Fikrian (2018) penelitiaanya mengatakan bahwa perguruan tinggi memainkan peran fungsionalnya dalam mempromosikan pendidikan kewirausahaan karena perguruan tinggi dianggap sebagai lembaga yang ideal dalam membentuk budaya dan aspirasi kewirausahaan dikalangan mahasiswa. Sudah semestinya perguruan tinggi menempatkan diri mereka sebagai pusat kewirausahaan dengan berkontribusi dalam memelihara sebuah lingkungan kewirausahaan yang menggabungkan faktor-faktor yang berkontribusi terhadap pengembangan kewirausahaan.

Boyd (2009), menjelaskan media sosial sebagai kumpulan perangkat lunak yang memungkinkan individu maupun komunitas untuk berkumpul, berbagi, berkomunikasi dan dalam kasus tertentu saling berkolaborasi atau bermain. Media sosial memiliki kekuatan pada user generated content (UGC) dimana konten dihasilkan oleh pengguna, bukan oleh editor sebagaimana di institusi media massa. Media sosial memliki beberapa karakter yang tidak dimiliki oleh beberapa jenis media lainnya. Nasrullah (2016) dalam (Pustasari,2018) seperti jaringan, informasi, arsip, interaksi, simulasi sosial, konten oleh pengguna, dan penyebaran.

Mahasiswa Fakultas Ekonomi dan Bisnis Universitas Mataram Tahun 2020/2021 berjumlah 4.893 orang, yang tersebar pada berbagai jurusan dan program studi. Dari jumlah mahasiswa hanya $0,61 \%$ mahasiswa yang sudah memulai berwirausaha (Data Primer diolah Tahun 2020, lampiran). Hal ini sangat disayangkan jika jumlah mahasiswa yang sudah berwirausaha masih sangat sedikit. Dengan demikian dibutuhkan peran kampus untuk 


\section{Elastisitas - Jurnal Ekonomi Pembangunan \\ Vol. 3 No. 2, September 2021}

memberikan edukasi di luar jam kuliah seperti terlaksananya kegiatan seminarseminar kewirausahaan yang dapat memberikan pengetahuan dan menambah wawasan terkait dengan sistem menjalankan bisnis disaat masih menempuh pendidikan, manajamen waktu yang baik sehingga tidak mengganggu proses perkuliahan dan tetap berprestasi dalam akademik. Dengan harapan dapat merubah maindset mahasiswa untuk tidak hanya berharap untuk menjadi ASN (Aparatur Sipil Negara) saja yang peluangnya sangat sedikit. Untuk itu diharapkan mahasiswa dapat memulai berwirausaha yang dapat dilakukan dengan hanya bermodalkan smartphon yang dimiliki dan dengan memanfaatkan media sosial yang sudah sering digunakan sebelumnya. Karena media sosial merupakan suatu wadah yang dapat digunakan untuk mulai berwirausaha dengan modal dan resiko yang minim. Dari uraian di atas tim penulis tertarik untuk meg kaji "Pengaruh Pemanfaatan Media Sosial Instagram Terhadap Minat Berwirausaha Mahasiswa Fakultas Ekonomi dan Bisnis Universitas Mataram".

\section{Rumusan Masalah}

Bagaimana pengaruh komunitas online, interaksi, akesesabilitas, terhadap minat berwirausaha mahasiswa Fakultas Ekonomi dan Bisnis.

\section{Tujuan Penelitian}

Untuk mengkaji pengaruh komunitas online, interaksi, aksesibilitas, terhadap minat berwirausaha mahasiswa Fakultas Ekonomi dan Bisnis.

\section{METODE PENELITIAN}

Jenis penelitian deskriptif kuantitatif dipilih karena rancangan dalam penelitian ini adalah menghitung dan menginterpretasikan seberapa besar hubungan dan pengaruh antara variabel independen dan variabel dependen.

\section{Jenis dan sumber data}

Menggunakan data primer yang diperoleh langsung dari jawaban responden dan data skunder sebagai pendukung.

\section{Populasi dan Sampel}

Populasi semua mahasiswa fakultas ekonomi dan bisnis angkatan 2018 sejumlah 1.443 orang dengan jumlah sampel sejumlah 94 orang yang di peroleh dengan menggunakan rumus solvin.

\section{Tehnik Pengumpulan Data}

1. Observasi Pengamatan terhadap objek penelitian.

2. Kuessioner

Daftar pernyataan atau pertanyaan yang dibuat guna mencarai data yang diinginkan.

3. Dokumentasi Analisis dokumen lebih mengarah pada bukti konkret.

\section{Skala pengukuran dan uji instrumen penelitian}

Penelitia menggunakan skala likert dan uji instrumen penelitian menggunakan uji validitas dan reabilitas.

\section{Uji validitas}

Uji validitas dilakukan dengan cara mengkorelasikan seluruh skor yang diperoleh dari masing-masing pertanyaan atau pernyataan, menentukan layak atau tidaknya suatu item yang akan digunakan, dilakukan uji signfikansi koefisien pada taraf signifikansi 0,05. Artinya, suatu item dianggap valid jika berkorelasi signifkan terhadap skor total atau instrumen dinyatakan valid apabila (r) hitung lebih besar dari (r) tabel (r.hit $>$ r.tabel), dan instrumen dinyatakan tidak valid apabila (r) hitung lebih kecil dari (r) tabel (r.hit $<$ r.tabel). 


\section{Uji reabilitas}

Uji validitas dilakukan dengan cara mengkorelasikan seluruh skor yang diperoleh dari masing-masing pertanyaan atau pernyataan, selanjutnya dalam menentukan layak atau tidaknya suatu item yang akan digunakan, dilakukan uji signfikansi koefisien pada taraf signifikansi 0,05. Artinya, suatu item dianggap valid jika berkorelasi signifkan terhadap skor total atau instrumen dinyatakan valid apabila (r) hitung lebih besar dari (r) tabel (r.hit > r.tabel), dan instrumen dinyatakan tidak valid apabila (r) hitung lebih kecil dari (r) tabel (r.hit < r.tabel).

\section{Uji Regresi Linier Berganda Persamaan Model Regresi}

$$
\begin{array}{ll}
\mathbf{Y} & =\mathbf{a}+\mathbf{b} 1 \mathbf{X} 1+\mathbf{b} 2 \mathbf{X} \mathbf{2}+\mathbf{b} 3 \mathbf{X} 3+\mathbf{e} \\
\mathrm{a} & =\text { Constanta } \\
\mathrm{X} 1 & =\text { komunitas Online } \\
\mathrm{X} 2 & =\text { interaksi } \\
\mathrm{X} 3 & =\text { Aksesabilitas } \\
\mathrm{b} 1, \mathrm{~b} 2, \mathrm{~b} 3 & =\text { koefisien regresi } \\
\mathrm{e} & =\text { eror }
\end{array}
$$

\section{Uji T ( Parsial)}

Digunakan untuk menguji koefisien regresi setiap variabel independen. Hal ini dilakukan untuk memastikan apakah variabel independen yang terdapat dalam suatu model secara individu berpengaruh terhadap nilai variabel dependen. Dasar pengambilan keputusan dengan melihat probabilitas signifikansi. Apa bila nilai probabilitas signifikansi $>0,05$ maka tidak terdapat pengaruh yang signifikan antara variabel independen dan variabel dependen. Begitupun sebaliknya.

\section{Uji F( Simultan )}

Digunakan untuk mengetahui apakah semua variabel independen mempunyai pengaruh yang signifikan terhadap variabel dependen. Dasar pengambilan keputusan dengan melihat probabilitas signifikansi. Apa bila nilai probabilitas signifikansi $>0,05$ maka tidak terdapat pengaruh yang signifikan antara variabel independen dan variabel dependen. Begitupun sebaliknya.

\section{Koefisien Determinasi}

Koefisien determinasi (R Square atau $\mathrm{R}^{2}$ ) yang bermakna sebagai sumbangan pengaruh yang diberikan variabel bebas atau variabel independen (X) terhadap variabel terikat atau variabel dependen (Y). Nilai koefisien determinasi ini berguna untuk memprediksi dan melihat seberapa besar kontribusi pengaruh yang diberikan variabel $\mathrm{X}$ secara simultan terhadap variabel $\mathrm{Y}$.

\section{Uji Asumsi Klasik}

Untuk meyakinkan bahwa persamaan garis regresi yang diperoleh adalah linier atau BLUE (Best Linear Unbiased Estimator) dan dapat dipergunakan (valid) untuk mencari peramalan, maka akan dilakukan pengujian asumsi multikolinearitas, heteroskedastisitas, dan normalitas

\section{Deteksi Multikolinearitas}

Deteksi multikolinearitas adalah untuk menguji apakah pada model regresi ditemukan adanya korelasi antar variabel bebas (independen). Apabila terjadi korelasi, maka dinamakan terdapat problem multikolinearitas (Ghozali, 2011). Untuk menguji ada atau tidaknya multikolinearitas di dalam model regresi dapat diliha dari tolerance value atau variance inflation factor (VIF). Batas dari tolerance value $>0,1$ atau nilai VIF lebih kecil dari 10 maka tidak terjadi multikolinieritas.

\section{Heteroskedastisitas}

Deteksi heteroskedastisita Adalah untuk menguji apakah dalam model regresi terjadi ketidaksamaan varians dari residual satu pengamatan ke pengamatan yang lain (Ghozali, 2011).pengambilan kesimpulan dengan melihat penyebaran titik (data) pada grafik plot. Apabila tidak 


\section{Elastisitas - Jurnal Ekonomi Pembangunan \\ Vol. 3 No. 2, September 2021}

terdapt pola tertentu dan titik(data) menyebar maka tidak terjadi maslah

\section{Normalitas}

Deteksi normalitas digunakan untuk menguji apakah dalam modelregresi, kedua variabel (bebas maupun terikat) mempunyai distribusinormal atau setidaknya mendekati normal (Ghozali, 2011).

\section{HASIL DAN PEMBAHASAN}

\section{Karakteristik Responden}

Tabel 1.4.

Distribusi Responden Berdasarkan Jenis Kelamin

\begin{tabular}{|c|l|r|r|}
\hline No & Jenis kelamin & \multicolumn{1}{c|}{ Jumlah } & \multicolumn{1}{c|}{$\%$} \\
\hline 1 & Laki - laki & 29 orang & $31 \%$ \\
\hline 2 & Perempuan & 65 orang & $69 \%$ \\
\hline \multicolumn{2}{|c|}{ Total } & $\mathbf{9 4}$ orang & $\mathbf{1 0 0} \%$ \\
\hline
\end{tabular}

Sumber : Data primer diolah tahun 2021

Darai tabel di atas mayoritas responden adalah dengan jenis kelamin perempuan yakni sebanyak 65 orang atau sekitar $(69 \%)$ dari total seluruh responden

Tabel 1.5

Distribusi Responden Berdasarkan Program Studi

\begin{tabular}{|l|l|c|c|}
\hline No & \multicolumn{1}{|c|}{ Program studi } & Jumlah & \% \\
\hline 1 & IESP & 38 orang & $40 \%$ \\
\hline 2 & Akuntansi & 16 orang & $17 \%$ \\
\hline 3 & Manajemen & 18 orang & $19 \%$ \\
\hline 4 & D3 Akuntansi & 10 orang & $11 \%$ \\
\hline 5 & D3 Perpajakan & 7 orang & $8 \%$ \\
\hline 6 & D3 Pariwisata & 5 orang & $5 \%$ \\
\hline \multicolumn{2}{|c|}{ TOTAL } & $\mathbf{9 4}$ orang & $\mathbf{1 0 0} \%$ \\
\hline
\end{tabular}

Sumber : Data primer diolah tahun 2021

Berdasarkan tabel di atas dapat diketahui responden terbanyak yakni dari program studi IESP sebanyak 38 orang (40\%) dari total seluruh responden.

Tabel1.6

Distribusi Jawaban Responden Berdasarkan Frekuensi Penggunaan Media Sosial Instagram

\begin{tabular}{|l|c|c|c|}
\hline No & \multicolumn{1}{|c|}{ Waktu } & Jumlah & $\mathbf{\%}$ \\
\hline 1 & $1-3 \mathrm{jam} / \mathrm{hari}$ & 38 orang & $40 \%$ \\
\hline 2 & $4-6 \mathrm{jam} / \mathrm{hari}$ & 30 orang & $32 \%$ \\
\hline 3 & $7-9 \mathrm{jam} / \mathrm{hari}$ & 13 orang & $14 \%$ \\
\hline 4 & $>9 \mathrm{jam} / \mathrm{hari} \quad 13$ orang & $14 \%$ \\
\hline \multicolumn{2}{|c|}{ TOTAL } & $\mathbf{9 4}$ orang & $\mathbf{1 0 0} \%$ \\
\hline
\end{tabular}

Sumber : Data primer diolah tahun 2021

Dapat disimpulkan bahwa mayoritas responden dalam menggunakan media sosial Instagram adalah 1-3 jam per hari yakni sebanyak 38 orang $(40 \%)$ dari seluruh responden 


\section{Elastisitas - Jurnal Ekonomi Pembangunan \\ Vol. 3 No. 2, September 2021}

\begin{tabular}{|l|c|c|c|}
\hline \multicolumn{1}{|c|}{ Variabel } & $\begin{array}{c}\text { Cronbach's } \\
\text { Alpha }\end{array}$ & Nilai kritis & Keterangan \\
\hline Komunitas online & 0,697 & 0,60 & Reliabel \\
\hline Interaksi & 0,683 & 0,60 & Reliabel \\
\hline Aksesabilitas & 0,689 & 0,60 & Reliabel \\
\hline Minat berwirausaha & 0,667 & 0,60 & Reliabel \\
\hline
\end{tabular}

Dengan demikian dari uji validitas dan reabilitas yang dilakukan diperoleh hasil bahwa semua item pertanyaan yang digunakan dalam penelitian dinyatakan valid dan reliabel

Uji Validitas

\begin{tabular}{|l|c|c|c|c|}
\hline $\begin{array}{c}\text { Item pernyataan (komunitas } \\
\text { Online) }\end{array}$ & R hitung & R tabel & Signifikan & Kesimpulan \\
\hline X1.1 & 0,819 & 0,202 & 0,000 & Valid \\
\hline X1.2 & 0,504 & 0,202 & 0,000 & Valid \\
\hline X1.3 & 0,658 & 0,202 & 0,000 & Valid \\
\hline
\end{tabular}

Sumber : data primer diolah tahun 2021

\begin{tabular}{|c|c|c|c|c|}
\hline $\begin{array}{c}\text { Item pernyataan } \\
\text { (interaksi) }\end{array}$ & R hitung & R tabel & Signifikan & Kesimpulan \\
\hline $\mathrm{X} 2.1$ & 0,319 & 0,202 & 0,000 & Valid \\
\hline $\mathrm{X} 2.2$ & 0,386 & 0,202 & 0,000 & Valid \\
\hline $\mathrm{X} 2.3$ & 0,382 & 0,202 & 0,000 & Valid \\
\hline
\end{tabular}

Sumber: data primer diolah 2021

\begin{tabular}{|c|c|c|c|c|}
\hline $\begin{array}{c}\text { Item pernyataan } \\
\text { (aksesabilitas) }\end{array}$ & R hitung & R tabel & Signifikan & Kesimpulan \\
\hline X3.1 & 0,563 & 0,202 & 0,000 & Valid \\
\hline X3.2 & 0,701 & 0,202 & 0,000 & Valid \\
\hline X3.3 & 0,717 & 0,202 & 0,000 & Valid \\
\hline
\end{tabular}

\begin{tabular}{|c|c|c|c|c|}
\hline $\begin{array}{c}\text { Item pernyataan(minat } \\
\text { berwirausaha) }\end{array}$ & R hitung & R tabel & Signifikan & Kesimpulan \\
\hline Y1 & 0,646 & 0,202 & 0,000 & Valid \\
\hline Y2 & 0,830 & 0,202 & 0,000 & Valid \\
\hline Y3 & 0,774 & 0,202 & 0,000 & Valid \\
\hline Y4 & 0,755 & 0,202 & 0,000 & Valid \\
\hline Y5 & 0,564 & 0,202 & 0,000 & Valid \\
\hline Y6 & 0,675 & 0,202 & 0,000 & Valid \\
\hline Y7 & 0,526 & 0,202 & 0,000 & Valid \\
\hline Y8 & 0,664 & 0,202 & 0,000 & Valid \\
\hline
\end{tabular}

\begin{tabular}{|l|r|r|r|r|l|}
\hline \multicolumn{1}{|c|}{ Variabel } & \multicolumn{1}{c|}{ Prediksi } & \multicolumn{1}{c|}{ Koefisien } & \multicolumn{1}{c|}{ T hitung } & \multicolumn{1}{c|}{ Signifikansi } & \multicolumn{1}{c|}{ Ket } \\
\hline (Constanta ) & - & 11,767 & 2,344 & 0,021 & - \\
\hline $\begin{array}{l}\text { Minat } \\
\text { Berwirausaha }\end{array}$ & - & & & & \\
\hline Komunitas online & - & 0,432 & 1,742 & 0,085 & Ditolak \\
\hline Interaksi & - & 0,515 & 2,368 & 0,020 & Diterima \\
\hline Aksesabilitas & - & 0,782 & 3,597 & 0,001 & Diterima \\
\hline R square & 0,187 & & & & \\
\hline Adjusted R2 & 0,160 & & & & \\
\hline F hitung & 6,920 & & & & \\
\hline
\end{tabular}


$\mathrm{Y}=11,767+0,432 \mathrm{X} 1+0,515 \mathrm{X} 2+0,782 \mathrm{X} 3+\mathrm{e}$

1. Uji t (Parsial)

a. Komunitas Online

Berdasarkan tabel 4.14 dapat diketahui nilai t hitung untuk variabel komunitas online sebesar 1,742< 1,978 dengan signifikansi $0,085>$ 0.05 .

b. Interaksi

Dapat diketahui nilai t hitung untuk variabel interaksi sebesar 2,368 >t tabel 1,978 dengan signifikansi 0,020 $<0.05$.sehingga dapat disimpulkan bahwa variabel X2 (interaksi) memiliki pengaruh yang signifikan terhadap variabel Y (minat berwirausaha).

c. Aksesabilitas

Dapat diketahui nilai t hitung untuk variabel aksesabilitas sebesar 3,597 > $\mathrm{t}$ tabel 1,978 dengan signifikansi $0,001<0.05$. sehingga dapat disimpulkan bahwa variabel X3 (akesabilitas) memiliki pengaruh yang signifikan terhadap variabel $\mathrm{Y}$ (minat berwirausaha).

\section{Uji F (Simultan}

Dapat diketahui nilai $\mathrm{F}$ hitung $=6,920$. Sedangkan pada $\mathrm{F}$ tabel diperoleh dengan rumus $\mathrm{FINV}=(0.05 ; 3 ; 90)=2,706$. Sehingga $\mathrm{F}$ hitung $=6.920>\mathrm{F}$ tabel $=$ 2,706 dan sig $0,000<0,05$. Dengan demikian secara bersama - sama semua variabel independen memiliki pengaruh terhadap variabel dependen.

3. Koefisien Determinasi (R Square)

Dapat diperoleh angka $\mathrm{R}^{2}(\mathrm{R}$ square ) sebesar 0,187atau 18,7\%. Hal ini menunjukkan bahwa persentase sumbangan pengaruh variabel independen terhadap variabel dependen hanya sebesar $18,7 \%$ dan sisanya sebesar $81,3 \%$ dipengaruhi oleh variabel variabel lainnya yang berada diluar model.
4. UJI ASUMSI KLASIK

1. Uji Multikoloniaritas

\begin{tabular}{|l|l|l|}
\hline \multicolumn{1}{|c|}{ Variabel } & $\begin{array}{c}\text { Nilai } \\
\text { Tolerance }\end{array}$ & Nilai VIF \\
\hline $\begin{array}{l}\text { Komunitas } \\
\text { online }\end{array}$ & 0,999 & 1,001 \\
\hline Interaksi & 0,996 & 1,004 \\
\hline Aksesabilitas & 0,996 & 1,004 \\
\hline
\end{tabular}

Sumber : Data primer diolah tahun 2021

Diperoleh nilai VIF untuk komunitas online, interaksi, dan aksesibilitas $<10$ dan nilai Tolerance $>0,1$ maka dapat disimpulkan bahwa model regresi bebas dari multikolinearitas atau tidak adanya masalah multikolinearitas.

\section{Uji Heteroskedastisitas}

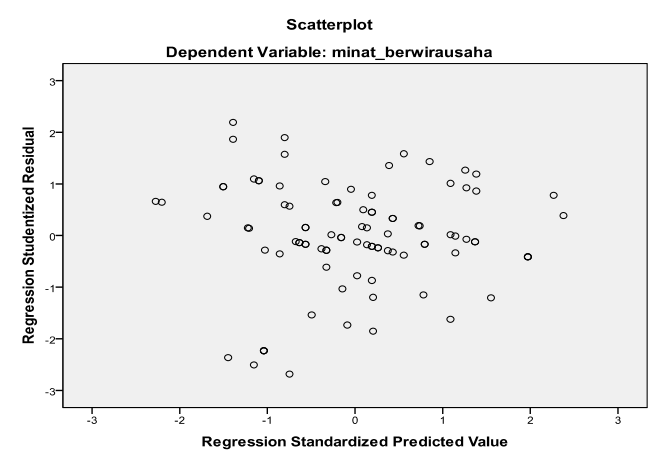

Berdasarkan gambar grafik tersebut dapat dilhat jika titik - titik menyebar di atas dan di bawah sumbu Y maka tidak terjadi masalah heteroskedastisitas dalam model.

\section{Uji Normalitas}

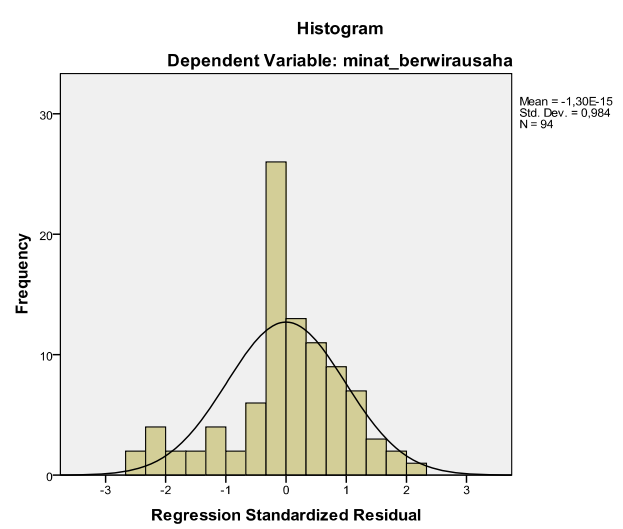


Berdasarkan grafik tersebut dapat dilihat jika data (titik) menyebar disekitar garis diagonal dan mengikuti arah garis diagonal atau grafik histogramnya menunjukkan pola distribusi normal, maka model regresi memenuhi asumsi normalitas.

\section{KESIMPULAN}

Dengan demikian secara parsial variabel komunitas online tidak berpengaruh terhadap variabel minat berwirausaha dan variabel interaksi dan aksesabilitas berpengaruh signifikan terhadap minat berwirausaha. Dan dengan uji simultan secara bersamaan semua variabel independen berpengaruh signifikan terhadap variabel dependen. Yang terakhir dengan uji asumsi klasik yang dilakukan model regresi yang digunakan memenuhi kriteria linier atau BLUE (Best Linier Unbisaide Estimator).

\section{SARAN}

Mahasiswa dapat bergabung dalam komunitas online yang ada sehingga tumbuhnya minat berwirausaha dan dibutuhkan peran kampus untuk memberikan pembelajaran wirausaha yang dapat dilakukan dengan mengadakan seminar - seminar kewirausahaan di luar jam kuliah sehingga mendorong minat mahasiswa dalam berwirausaha.

\section{REFERENSI}

Anonomi, 2020. Nusa Tenggara Barat Dalam Angka, Badan Pusat Statistik Nusa Tenggara Barat, Mataram.

Andi Dwi Riyanto. "Hootsuite (We Are Social): Indonesian Digital Report 2020 - Andi Dwi Riyanto, Dosen, Praktisi, Konsultan, Pembicara: EBisnis/Digital
Marketing/Promotion/Internet Marketing, SEO, Technopreneur, Fasilitator Google Gapura Digital Yogyakarta." Andi.link, 2020, andi.link/hootsuite-we-are-socialindonesian-digital-report-2020/.

Ghozali, I. (2011). Aplikasi Analisis Multivariate Dengan Program SPSS. Semarang: Badan Penerbit Universitas Diponegoro

Deslima, Y. D. (2018). Pemanfaatan Instagram Sebagai Media Dakwah Bagi Mahasiswa Komunikasi Dan Penyiaran Islam UIN Raden Intan Lampung. Lampung: UIN Raden Intan Lampung. Skripsi

Puspitasari, D. (2018). Pengaruh Terpaan Video Beauty Vlogger Di Youtube Terhadap Perilaku Imitasi Mahasiswi Dalam Merias Wajah(Studi pada Mahasiswa Ilmu Komunikasi Universitas Muhammadiyah Malang Angkatan 2013. Malang: University Of Malang.http://eprints.umm.ac.id/406 01/3/BAB\%20II.pdf

Chusumastuti, D. (2020). Pengaruh Pemanfaatan Media Online Terhadap Minat Berwirausaha Pada Mahasiswa (Studi Kasus Disekolah Tinggi Multi Media "MMTC" Yogyakarta ).Jurnal Riset Inspirasi Manajemen dan Kewirausahaan.

Fikrian, M. (2018). Analisis Peran Media Sosial Instagram Terhadap Minat Berwirausaha Mahasiswa Dalam Persektif Ekonomi Islam ( Studi Pada Mahasiswa Fakultas Ekonomi Dan Bisnis Islam Universitas Islam Negeri Raden Intan Lampung Angkatan 2014) . Jurnal, Ekonomi dan Bisnis, Universitas Islam Negeri Raden Intan Lampung. Vol. 2, No 2, 2018 
Yudi Siswadi 2013 Analisis Faktor Internal, Faktor Eksternal Dan Pembelajaran Kewirausahaan Yang Mempengaruhi Minat Mahasiswa Dalam Berwirausaha. Jurnal Manajemen dan Bisnis, Vol. 3 no 1 20 
Elastisitas - Jurnal Ekonomi Pembangunan

Vol. 3 No. 2, September 2021 